\title{
RACISM AND DISCRIMINATION： LET'S PRACTICE WHAT WE PREACH
}

\begin{abstract}
With the world in turmoil, an unexpected and tragic consequence of the SARS-CoV-2 pandemic has been its disproportionate impact on the British Asian and Minority Ethnic (BAME) communities. The pandemic led to an excessive number of deaths in these populations and revealed long-standing inequalities that began many years ago. This indictment raises questions about the extent to which racism and discrimination remain deeply rooted in British society. Have the diverse groups that together constitute the rich fabric of British society not heard, or do they choose to be deaf and blind to the suffering caused by racism and discrimination?
\end{abstract}

Keywords

BAME, racial discrimination, pay-gap, differential attainment
Neena Modi1, Parveen

Kumar2 and Mala Rao1

1Imperial College London

2Barts and the London,

Queen Mary University of

London

DOI: $10.38192 / 13.3 .19$

Article Information

Submitted 29.08.2020

Accepted 30.08.2020

Published 30.08.2020

Open Access

Creative Commons Licence v4.0

Full Text

Racism can be an individual or an institutional problem, but both are born from pervading prejudices, attitudes, and culture. Ethnic minorities are overrepresented in the more disadvantaged ends of society, with poorer incomes, housing and education, and lack opportunities available for the better off. However, let us not forget that the British rich list also consistently incudes at the top, members of the BAME communities. For most

of the population however, disparities are widespread and occur throughout the NHS and academia as well. Sadly, racism is just one of the many prejudices that exist which include those against sex, age, disability, religious belief, and sexual orientation.

In this article, we try to provide a constructive approach to the problem of inequalities and inequities.
- What can be done by the individual and what can society do?

- How can BAME professionals support, and build resilience and confidence in their communities?

The simple answer to the question implicit in the title of this commentary, is that BAME professionals expect fair treatment, and should adhere themselves to the same equitable standards they expect of others.

So how could BAME professionals contribute to actions to address racism and discrimination?

First, we need to know the facts. There is a growing body of evidence on how racism and discrimination result in variations in access to health care, and also act through biological pathways leading to a disproportionately greater burden of disease (1). The British Medical Journal's special issue on Racism in 
Medicine (2) this year was but one recently published concentrated source of facts, figures and information. It was also a reminder of how much more we need to know, given the scale of the challenges facing the NHS workforce and our communities. Evidence gathering and sharing need to be an ongoing process, one that this journal is ideally placed to lead.

Second, we need to act on the evidence already available. Until now, research has focused mainly on understanding how personal discrimination affects health, but the disproportionate impact of COVID-19 on the BAME communities has shifted the spotlight on to the hitherto neglected dimension of structural and institutional racism.

As far back as in 2004, the Health Survey for England showed the health inequalities with the lives of white English people aged 61-70 to be equivalent to that of Caribbean people in their late 40 s or early 50 s, Indians in their early 40 s, Pakistanis in their late 30s, and Bangladeshis in their late 20 s or early 30 s (3).

BAME professionals have the voice and leadership to investigate and help address the lifetime of disadvantage and discrimination which this reflects. However, our influence and impact must depend on whether we face up to our own biases. For example, to what extent are Asian male doctors in the NHS committed to supporting BAME female peers to achieve their full potential and get the recognition they deserve?

Research has shown that within different ethnic groups, Asian British women staff have the largest gender pay gap (4), a finding confirmed by the NHS Digital analysis of ethnic pay gaps among all NHS medical staff (5). We note that Asian male medical staff have been most successful in narrowing the pay gap in comparison with their white male counterparts. We have also pointed out the continuing gender imbalance that is evident in many BAME professional organisations.

Studies carried out across several decades have also consistently demonstrated differential attainment by ethnicity in the medical workforce across all measures of training and career progression. Furthermore, in a hierarchy of differential attainment, BAME UK medical graduates perform better than their international peers. The British Association of Physicians of Indian Origin (BAPIO's) commitment to race equality could not have been better demonstrated than in 2014, when the organisation challenged the lawfulness of the Royal College of General Practitioner's clinical skills examination which ethnic minority UK graduates were nearly 4 times, and international medical graduates 14 times as likely to fail in their first attempt, compared with white candidates (5). Six years later, differential attainment remains unresolved.

Many BAME medical professionals are now involved in specialty training. However, what evidence is there, that they are actively working to support the international medical graduates recruited to the NHS each year, whose educational and career attainments appear destined to remain at the bottom of the hierarchy?

\section{Conclusions}

Experiences of racism differ between individuals, as have ours. Therefore, we know it can be difficult to "put oneself fully into another's shoes". However, we must try to understand, because racism can leave permanent emotional scars and as we have seen in the case of George Floyd, Steven Lawrence and far, far too many others, can lead to death and lasting damage to communities.

Racism is real and each one of us has an obligation to call it out. We would prefer to focus actions on root causes, legal protections, and societal and attitudinal change. We do not believe that erasing evidence of historical racism is helpful. History is a great teacher, and as Theodore Roosevelt once remarked, "the more you know about the past, the better prepared you are for the future". If humankind is to eliminate racism, future generations need evidence that it existed; removing such evidence from memory would be totally counterproductive.

As protests against racism sweep across the world we must guard against the danger that views, beliefs and perceptions will be polarised, distorted or even willfully misappropriated, and that legitimate dialogue will be stifled. It would also be honest to accept that racism is a deeply 
rooted and profoundly unpleasant component of all humans and not the prerogative of any one group, race, or section of society. White on white, brown on brown, black on black racism not only exists, but also has led to the most horrific genocides the world has seen, such as in Nazi Germany, the Indian sub-continent, and Rwanda to name only a few examples.

Additionally, racism shares features with other forms of discrimination, such as those predicated on sex, age, disability, belief, sexual orientation, marital status and pregnancy, and many individuals will suffer on several counts. Our personal experiences of sexism and misogyny from members of our own communities have been as great as our experience of racism. Therefore, as the world rightly calls for an end to racism, we ask also for an end to all forms of discrimination.

We end with quoting Mahatma Gandhi, let us "be the change that you wish to see in the world".

\section{References}

1. Evans MK, Rosenbaum L, Malina D, Morrissey S, Rubin EJ. Diagnosing and treating systemic racism. N Engl J Med 2020. 383;3:274-276

2. The BMJ. Born Equal? Racism in medicine. 2020. 368:211-260

3. Becares L, Kapadia D, Nazroo J. Population research ignores older people from ethnic minority backgrounds. BMJ 2020;368:m212
4. Schlepper L, Appleby J. 2018. The gender pay gap in the English NHS: how does it vary by ethnicity? Nuffield Trust https://www.nuffieldtrust.org.uk/newsitem/the-gender-pay-gap-in-theenglish-nhs-how-does-it-vary-byethnicity

5. NHS Digital. NHS basic pay. Ethnicity facts and figures. Published 27 September 2018, updated on 14 May 2019. https://www.ethnicity-factsfigures.service.gov.uk/workforce-andbusiness/public-sector-pay/nhs-basicpay/latest

\section{Author's Biographies}

Neena Modi is professor of Neonatal Medicine, Imperial College London; president of the UK Medical Women's Federation and immediate past-president of the Royal College of Paediatrics and Child Health; the views expressed are her own.

Parveen Kumar is professor of Medicine and Education at Barts and the London School of Medicine, Queen Mary University of London and past president of the UK Medical Women's Federation; the views expressed are her own.

Mala Rao is professor of Public Health, Imperial College London; medical adviser Workforce Race Equality Strategy NHS England and co-founder of the NHS Race and Health Observatory; the views expressed are her own. 